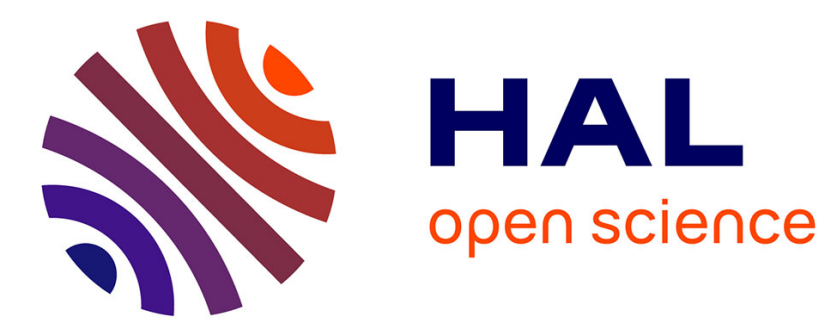

\title{
Photoinduced electrochemiluminescence at nanostructured hematite electrodes
}

\author{
Jing Yu, Hiba Saada, Neso Sojic, Gabriel Loget
}

\section{To cite this version:}

Jing Yu, Hiba Saada, Neso Sojic, Gabriel Loget. Photoinduced electrochemiluminescence at nanostructured hematite electrodes. Electrochimica Acta, 2021, 381, pp.138238. 10.1016/j.electacta.2021.138238 . hal-03190652

\section{HAL Id: hal-03190652 \\ https://hal.science/hal-03190652}

Submitted on 6 Apr 2021

HAL is a multi-disciplinary open access archive for the deposit and dissemination of scientific research documents, whether they are published or not. The documents may come from teaching and research institutions in France or abroad, or from public or private research centers.
L'archive ouverte pluridisciplinaire HAL, est destinée au dépôt et à la diffusion de documents scientifiques de niveau recherche, publiés ou non, émanant des établissements d'enseignement et de recherche français ou étrangers, des laboratoires publics ou privés. 


\title{
Photoinduced electrochemiluminescence at nanostructured hematite electrodes
}

\author{
Jing $\mathrm{Yu}^{\mathrm{a}}$, Hiba Saada ${ }^{\mathrm{b}}$, Neso Sojic ${ }^{\mathrm{a}^{*}}$, Gabriel Loget ${ }^{\mathrm{b} *}$
}

a. University of Bordeaux, Bordeaux INP, ISM, UMR CNRS 5255, 33607 Pessac,

France

*neso.sojic@enscbp.fr

b. Univ Rennes, CNRS, ISCR (Institut des Sciences Chimiques de Rennes)-UMR6226 ScanMAT-UMS2001, F-35000 Rennes, France

*gabriel.loget@univ-rennes1.fr

\section{Keywords}

Photoelectrochemistry, electrochemiluminescence, hematite, semiconductors, luminol

\begin{abstract}
In this article, we study the photoinduced electrochemiluminescence (PECL) of a luminol analog (L-012: 8-amino- 5-chloro-2,3-dihydro-7-phenyl-pyrido[3,4-d]pyridazine-1,4-dione) on n-type hematite $\left(\alpha-\mathrm{Fe}_{2} \mathrm{O}_{3}\right)$ nanorod arrays deposited by hydrothermal synthesis on a transparent conducting oxide. We report that this material, when used as a photoanode, triggers PECL at a potential as low as $-0.2 \mathrm{~V}$ vs $\mathrm{Ag} / \mathrm{AgCl}$ and allows the amplification of the luminescence signal. The PECL concept should open up new perspectives based on lightaddressable strategies in bioanalysis and imaging.
\end{abstract}




\section{Introduction}

Electrochemiluminescence (ECL) is a light-emitting phenomenon triggered by electrochemical means [1-3]. In ECL, light generation is induced by the excited state of a luminophore, which is electrochemically-generated by a cascade of redox reactions in the immediate vicinity of the electrode surface. ECL is a well-established analytical method, especially for immunoassays, and is emerging as a powerful imaging technique [4-10]. The majority of these applications relies on the use of model ECL luminophores such as the tris(bipyridine)ruthenium(II) $\left(\left[\mathrm{Ru}(\mathrm{bpy})_{3}\right]^{2+}\right)$ or luminol (3-aminophthalhydrazide) and their analogs [11-22]. For example, L-012 (8-amino- 5-chloro-2,3-dihydro-7-phenyl-pyrido[3,4d]pyridazine-1,4-dione), a luminol-based analog, is widely used in vitro and in vivo to measure the activity of oxidase enzymes, to detect reactive oxygen species (ROS), and to measure different analytes at the cell level [23-28]. Compared to luminol, it generates ECL with a higher efficiency [23,27]. These model ECL reactions requires the application of anodic potential, typically $>1.1 \mathrm{~V}$ vs $\mathrm{Ag} / \mathrm{AgCl}$ for the tris(bipyridine)ruthenium(II) $\left(\left[\mathrm{Ru}(\mathrm{bpy})_{3}\right]^{2+}\right) /$ tri-n-propylamine system and $>0.3 \mathrm{~V}$ for luminol analogs. Depending on the electrode material (e.g., ITO), higher anodic potentials such as $+1 \mathrm{~V}$ may be required for L012 to obtain brighter emission [27,28]. On the other hand, in semiconductors photoelectrochemistry, a depleted semiconductor absorbs photons of higher energy than its bandgap $\left(E_{\mathrm{g}}\right)$ for triggering electrochemical reactions at a solid/liquid interface. In this approach, the high oxidation potential of photogenerated minority carriers allows to considerably decrease the onset potential of the electrochemical reaction $[29,30]$.

The combination of ECL and semiconductors photoelectrochemistry is referred to as photoinduced-electrochemiluminescence (PECL) [31]. This concept enables the conversion of an input light signal (photons absorbed by the semiconductor, $\lambda_{\text {exc }}$ ) to an output light signal (photons emitted by the ECL process, $\lambda_{\mathrm{em}}$ ). Besides, PECL is also promising as it enables the 
local emission of ECL triggered by a focalized spot of light and can therefore be used for performing multiple assays on a single surface [32,33]. PECL has been initially demonstrated using annihilation ECL in organic solvents by Bard et al. [34,35] and, more recently, in an aqueous electrolyte with the coreactant ECL system $\left[\mathrm{Ru}(\mathrm{bpy})_{3}\right]^{2+} / \mathrm{TPrA}[31]$ and with luminol analogs $[32,36]$ by our group and others. In most of these works, Si or III-V-based semiconductor surfaces were employed as photoelectrodes [31,32,34,35]. These materials hold some advantages such as the fact that they are commercially available and they have high carrier mobilities. In addition, their electronic structure can be tuned in a very precise way. However, they also exhibit drawbacks such as their price or their instability caused by photocorrosion [37]. The latter aspect is a particular issue for their long-term use in aqueous electrolytes [38] and implies the use of protection layers [31]. Conversely, oxide-based semiconductors usually involve lower processing costs and exhibit better resistance to photocorrosion, which make them particularly interesting for PECL. To the best of our knowledge, so far, only one report on PECL focused on an oxide semiconductor (i.e., $\mathrm{BiVO}_{4}$ ) [36]. Among n-type semiconductors that are promising for photoelectrochemical applications, hematite $\left(\alpha-\mathrm{Fe}_{2} \mathrm{O}_{3}\right)$ attracts attention. It shows a peculiar [39], yet controversial [40] photoelectrochemical behavior and has been employed in particular in the fields of water splitting [41-44] and photoelectrochemical sensing [45,46] due to its high theoretical photoconversion efficiency, its low cost, its chemical stability, and its good biocompatibility. Interestingly, $\alpha-\mathrm{Fe}_{2} \mathrm{O}_{3}$ also exhibits much lower carrier mobility and higher recombination rates than Si or III-V-based semiconductors. If this is generally considered as a major issue in photoconversion application, it has been recently shown that it can be used as a strong advantage for improving resolution in light-addressable electrochemistry with $\alpha-\mathrm{Fe}_{2} \mathrm{O}_{3}$ systems [47], which makes this material particularly relevant for localized PECL. 
In this article, we study the PECL of L-012, a luminol analog on nanostructured $\alpha-\mathrm{Fe}_{2} \mathrm{O}_{3}$ photoanodes. We show that this material allows for luminescence amplification with good temporal stability, which should open up important perspectives for PECL.

\section{Materials and methods}

\subsection{Materials and reagents}

Fluorine-doped $\mathrm{SnO}_{2}$ (FTO)-covered glass plates, urea $(\geq 99 \%), \mathrm{NaOH}(>99.8 \%)$, and iron chloride hexahydrate $\left(\mathrm{FeCl}_{3} .6 \mathrm{H}_{2} \mathrm{O}, \geq 98 \%\right)$ were bought from Sigma-Aldrich. Teflon (PTFE) lined hydrothermal synthesis autoclave reactor $(25 \mathrm{ml})$. Acetone (technical grade, VWR) and ethanol (96\%, Carlo Erba) were used as received. The resistivity of ultrapure water was 18.2 $\mathrm{M} \Omega \mathrm{cm}$ (Purelab Classic UV, Veolia). 8-amino- 5-chloro-2,3-dihydro-7-phenyl-pyrido[3,4d]pyridazine-1,4-dione (L-012) was purchased from FUJIFILM Wako Chemicals Europe $\mathrm{GmbH}$.

\subsection{Synthesis and characterization of the photoelectrodes}

The FTO slides $\left(1 \times 2 \mathrm{~cm}^{2}\right)$ were cleaned with a detergent (110551, Ecolab), rinsed copiously with deionized water, and sonicated for 10 min successively in acetone, ethanol, and ultrapure water. The backside of the FTO substrate (the glass side) was covered with an adhesive tape and vertically placed in the reactor, which was filled with $20 \mathrm{~mL}$ of an aqueous solution containing $0.1 \mathrm{M} \mathrm{FeCl}_{3} .6 \mathrm{H}_{2} \mathrm{O}$ and $0.15 \mathrm{M}$ urea. The reactor was sealed and heated in an oven at $100{ }^{\circ} \mathrm{C}$ for $16 \mathrm{~h}$. After the reaction, the films were sonicated in water for $20 \mathrm{~min}$ and were annealed in air successively at $500{ }^{\circ} \mathrm{C}$ for $3 \mathrm{~h}$ and $750{ }^{\circ} \mathrm{C}$ for $10 \mathrm{~min}$ in a tubular oven. X-ray diffraction (XRD) analysis was performed on a Rigaku Smartlab X-Ray diffractometer (5-axis goniometer, working conditions: $40 \mathrm{kV}, 50 \mathrm{~mA}(2.0 \mathrm{~kW}), \mathrm{Cu}$ cathode). Scanning electron microscopy (SEM) was performed using a JSM 7100F (JEOL). The colorized SEM pictures were prepared using the Inkscape freeware. 


\subsection{Photoelectrochemical measurements}

Cyclic voltammetry (CV) and chronoamperometry (CA) measurements were performed with a $\mu$-Autolab Type III (Metrohm) connected with a 3-electrodes cell. The FTO/ $\alpha-\mathrm{Fe}_{2} \mathrm{O}_{3}$ substrate was the working electrode, an $\mathrm{Ag} / \mathrm{AgCl}(3 \mathrm{M} \mathrm{NaCl})$ electrode was used as the reference electrode and a carbon rod was the counter electrode. The scan rate of the CVs was $20 \mathrm{mV} \mathrm{s}^{-1}$. The FTO/ $\alpha-\mathrm{Fe}_{2} \mathrm{O}_{3}$ surface was sealed with an O-ring in a home-made open-top cell (the photoelectrochemically active surface area was $\sim 0.3 \mathrm{~cm}^{2}$ ). A copper tape connected to the FTO was used as an electrical contact. The electrolyte $(5 \mathrm{~mL})$, composed of $10 \mathrm{mM} \mathrm{L-012}$ dissolved in $0.1 \mathrm{M} \mathrm{NaOH}$ was freshly prepared and disposed in the cell and the other two electrodes were placed on the sides in order to prevent shadowing of the front surface. A 375 nm light-emitting diode (LED, 733-4745, Radiospares) coupled with a low bandpass filter was placed below the photoanode to illuminate the backside of $\mathrm{FTO} / \alpha-\mathrm{Fe}_{2} \mathrm{O}_{3}$ (through the FTO). The LED power was controlled by a power generator. ECL spectra were recorded using a spectrograph Spectra pro 2300i (Princeton Instrument) connected with a collecting optical fiber under different potentials with an exposure time of $1 \mathrm{~s}$. The optical fiber was placed above the electrolyte/air interface and at a distance of about $4 \mathrm{~cm}$ from the electrode to fiber. The PECL and fluorescence (FL) spectra were recorded with a constant LED current of $150 \mathrm{~mA}$ (corresponding to a power of $15 \mathrm{~mW}$ ). The FL spectra were acquired when LED was on but without applying a potential to the electrode. In Figures 4 and 6, the spectrum obtained in the dark under open-circuit conditions was used as a background and subtracted from the spectra. The PECL intensity (Figure 5) was obtained by subtracting the FL signal (recorded at the open circuit with the LED ON) from the PECL+FL signal (recorded upon the application of a potential). The stability test was done at $\mathrm{E}=0 \mathrm{~V}$ under intermittent light emission with an exposure time of $10 \mathrm{~s}$. To reduce the noise level and allows for better visualization of the PECL data, the spectra shown in Figure 5 were smoothed by adjacent averaging. 


\section{Results and discussion}

\subsection{Preparation of the hematite photoanodes}

FTO slides were modified by a previously-reported hydrothermal process in a solution containing $\mathrm{FeCl}_{3}$ and urea heated at $100{ }^{\circ} \mathrm{C}$ for $16 \mathrm{~h}$ (see the experimental section for more details) [48]. After the modification, the substrates were annealed in the air to crystallize the synthesized layer. Then, the surfaces were analyzed by energy-dispersive X-ray spectroscopy (EDS) and XRD. The EDS spectrum, presented in Figure 1a, shows that the surface comprises $\mathrm{O}, \mathrm{Fe}, \mathrm{Sn}$, and $\mathrm{Si}$, as expected for a glass-coated FTO slide covered by $\alpha-\mathrm{Fe}_{2} \mathrm{O}_{3}$ layer [49]. In the recorded XRD pattern, shown in the bottom panel of Figure 1b, all peaks of the FTO substrate can be observed (green lines in the top panel) and all other peaks can be attributed to the deposited $\alpha-\mathrm{Fe}_{2} \mathrm{O}_{3}$ layer (red lines in the top panel), revealing the rhombohedral crystalline nature of our $\alpha-\mathrm{Fe}_{2} \mathrm{O}_{3}$ coating. The morphological analysis was performed by SEM. Cross-section (Figure 1c) and top-view (Figure 1d) observations revealed that the $\alpha$ $\mathrm{Fe}_{2} \mathrm{O}_{3}$ (red color) covered homogeneously the FTO surface. The coating was composed of $550 \mathrm{~nm}$-long nanorods aligned perpendicular to the FTO surface, in good agreement with previous reports [50]. 

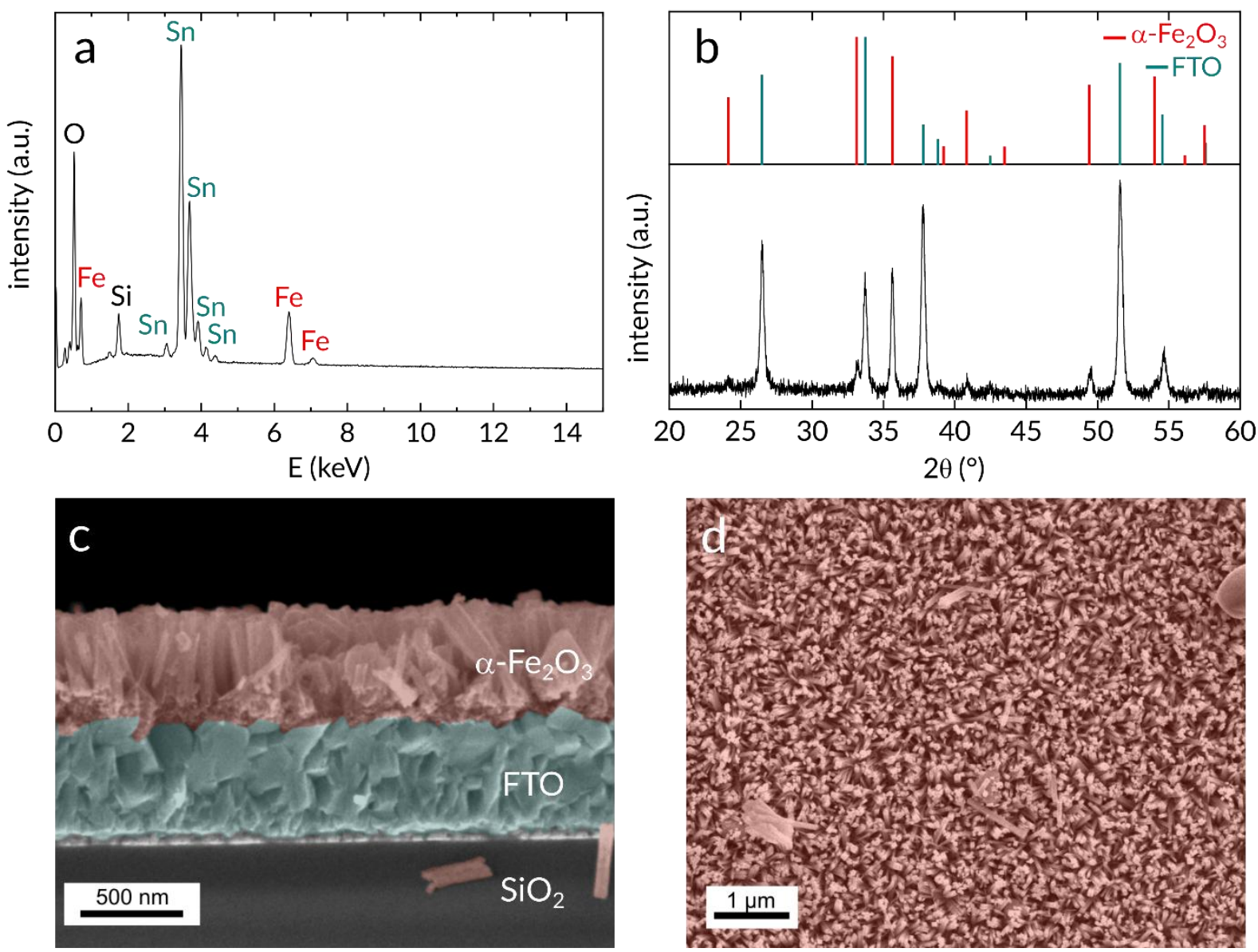

Figure 1. a) EDS spectrum of a $\mathrm{FTO} / \alpha-\mathrm{Fe}_{2} \mathrm{O}_{3}$ photoanode. b) Experimentally-determined XRD pattern of a photoanode (black curve of the bottom panel), theoretical peaks positions and relative intensities for hematite (ICSD \#15840, red lines of the top panel) and FTO (ICSD \#39178, green lines of the top panel). c) Cross-section and d) top-view colored SEM images of a $\mathrm{FTO} / \alpha-\mathrm{Fe}_{2} \mathrm{O}_{3}$ surface used as a photoanode in this study.

Such a nanorod array morphology is particularly interesting to be used in a photoelectrode design because it is expected to provide a beneficial short pathway (smaller than the rod diameter) for the diffusion of the photogenerated minority carriers, (minimization of bulk recombination rates before reaching the solid/liquid interface) coupled with a transversal path for majority carrier transport to the FTO collector [51]. 


\subsection{Photoelectrochemical characterization}

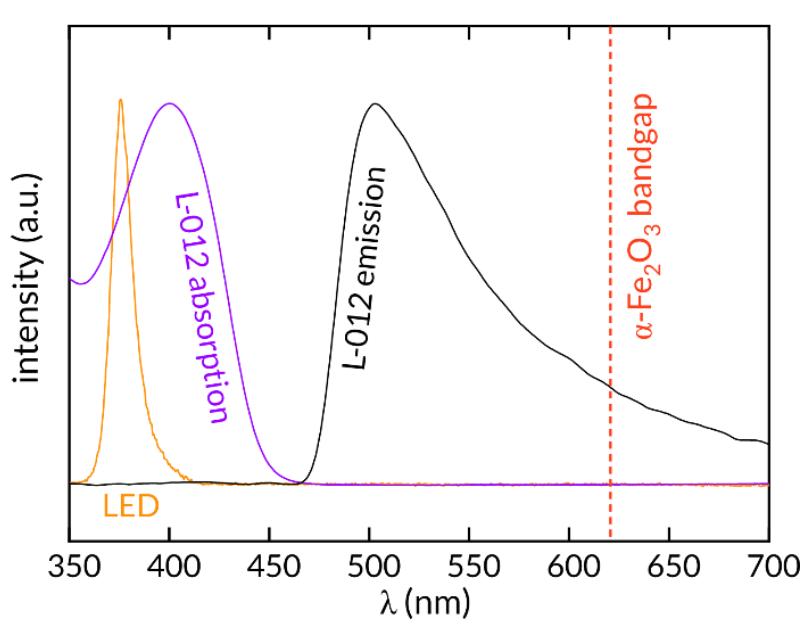

Figure 2. Normalized spectra showing the emission of the LED used in this work (orange), L012 absorption (purple) and the emission of L-012 (black), the two last spectra were recorded in $0.1 \mathrm{M} \mathrm{NaOH}$ with a L-012 concentration of $10 \mathrm{mM}$. The experimentally-determined bandgap of $\alpha-\mathrm{Fe}_{2} \mathrm{O}_{3}$ is represented by the red dotted line.

The anodic response of the $\mathrm{FTO} / \alpha-\mathrm{Fe}_{2} \mathrm{O}_{3}$ photoanode was studied in the PECL electrolyte containing L-012 dissolved in an alkaline aqueous solution at a $\mathrm{pH}$ that has been shown compatible with $\alpha-\mathrm{Fe}_{2} \mathrm{O}_{3}$ photoanodes [43]. L-012 was chosen as an ECL luminophore for several reasons: i) it allows for ECL generation at a relatively low applied potential at conventional conductive electrodes (e.g., > $0.3 \mathrm{~V} v s \mathrm{Ag} / \mathrm{AgCl}$ at glassy carbon electrode surface), ii) it produces brighter ECL emission than luminol, and, iii) it has been recently demonstrated efficient for triggering PECL at another oxide photoanode $\left(\mathrm{BiVO}_{4}\right)$ [36]. Here, we studied "fluorescence-type" PECL, which means that $\lambda_{\mathrm{exc}}<\lambda_{\mathrm{em}}[36]$, which differs from "up-conversion-type" PECL, where $\lambda_{\mathrm{exc}}>\lambda_{\mathrm{em}}[31,32,34,35]$. In other words, both fluorescence and PECL are photogenerated in the reported configuration. We selected a 10 $\mathrm{mM}$ concentration of $\mathrm{L}-012$ in this work because it corresponds to a good compromise between the PECL signal and the fluorescence one. The photoelectrochemical cell was similar to the one reported previously [36], allowing for a backside illumination (through the FTO) of 
the photoanode with a $375 \mathrm{~nm}$ LED (i.e., $\lambda_{\text {exc }}$ ). Due to the pseudo-transparency of the FTO/ $\alpha$ $\mathrm{Fe}_{2} \mathrm{O}_{3}$ substrate, as illustrated in the spectra of Figure 2, this configuration enables the excitation of the photoactive $\alpha-\mathrm{Fe}_{2} \mathrm{O}_{3}$ layer (bandgap $=2 \mathrm{eV}$, determined by photocurrent spectroscopy) as well as the fluorescence (FL) of L-012 (which absorbs below $465 \mathrm{~nm}$ ) $[36,52,53]$, to yield emission at $\sim 500 \mathrm{~nm}$. Additional spectra recorded in the absence of L012, revealed that photoluminescence signals from the semiconductor layer [54] were not detected in our experimental conditions.

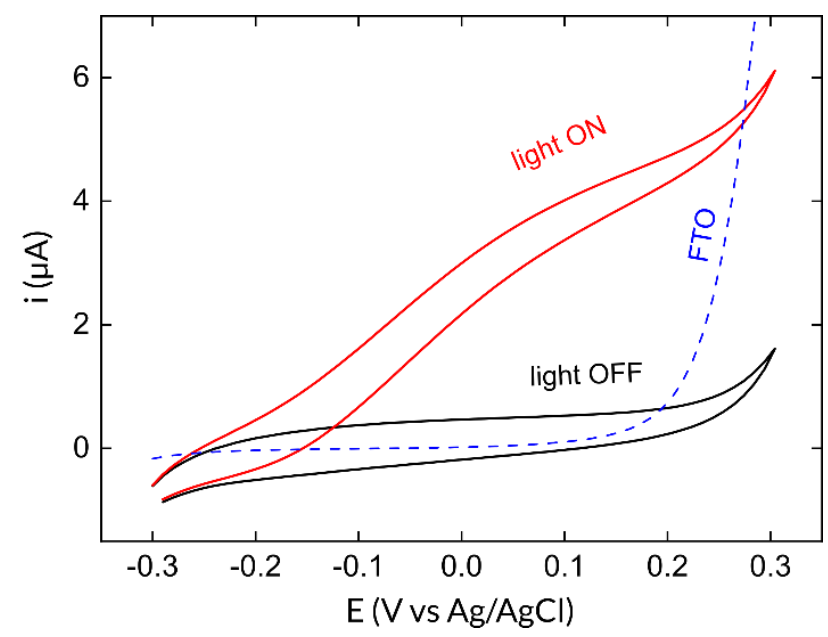

Figure 3. Cyclic voltammograms recorded on $\mathrm{FTO} / \alpha-\mathrm{Fe}_{2} \mathrm{O}_{3}$ at $20 \mathrm{mV} \mathrm{s}^{-1}$ in the dark (black curve) and under LED illumination at $375 \mathrm{~nm}$ (red curve). A linear sweep voltammogram recorded on bare FTO under LED illumination at $375 \mathrm{~nm}$ is also reported (dashed blue curve). The measurements were recorded in $0.1 \mathrm{M} \mathrm{NaOH}$ with an L-012 concentration of $10 \mathrm{mM}$.

Typical cyclic voltammograms recorded for that system are presented in Figure 3. In the dark (i.e., light OFF), the voltammetric response (black curve) indicates that negligible current densities are obtained at potentials comprised between $-0.3 \mathrm{~V}$ and $0.25 \mathrm{~V}$. However, the voltammogram (red curve) recorded under backside illumination at $375 \mathrm{~nm}$ (i.e., light $\mathrm{ON}$ ) shows that a photocurrent in the $\mu \mathrm{A}$ range appears. In these conditions, the current density starts to increase around $-0.2 \mathrm{~V}$ and tends to a quasi-plateau at $\sim 0.15 \mathrm{~V}$. This situation strongly differs with that recorded at a bare FTO surface (dashed blue curve). Indeed, 
voltammetry performed in the same conditions with an FTO electrode revealed that illumination has no effect on the voltammogram curve and an anodic activity that starts at $\sim 0.2 \mathrm{~V}$. This control experiments highlights the importance of the nanostructured $\alpha-\mathrm{Fe}_{2} \mathrm{O}_{3}$ coating for providing photoelectrochemical activity and promoting anodic behavior at low overpotentials. In this work, we observe the concomitant oxidation of L-012 and the ECL emission (vide infra) at the $\mathrm{FTO} / \alpha-\mathrm{Fe}_{2} \mathrm{O}_{3}$ photoelectrode. Luminol and its analogs such as L012 may emit ECL under a wide range of experimental conditions [55,56]. Indeed, ECL emission may result from several competitive mechanistic pathways with and without additional reagents (e.g., hydrogen peroxide, dioxygen, etc.). In brief, the electrochemical oxidation of L-012 produces a 5-aminophthalazine-1,4-dione form. The addition of $\mathrm{OH}^{-}$ associated with the subsequent electrochemical oxidation and $\mathrm{N}_{2}$ elimination generates the electronically excited state of the monoanions of the 3-aminophthalic acid form [55]. This latter relaxes to the ground state by emitting a photon in the blue region.

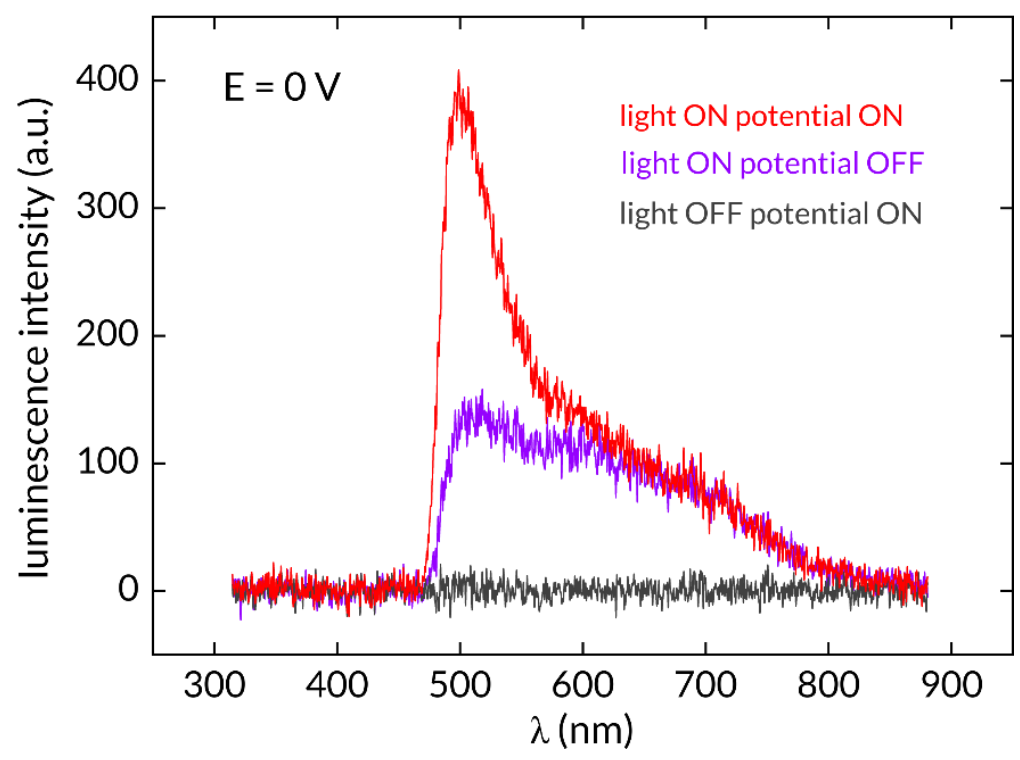

Figure 4. Luminescence spectra recorded at $0 \mathrm{~V}$ in the dark (black curve), at open circuit under LED illumination (purple curve), and at $0 \mathrm{~V}$ under LED illumination (red curve). The measurements were recorded in $0.1 \mathrm{M} \mathrm{NaOH}$ with an L-012 concentration of $10 \mathrm{mM}$. 
Emission spectra of L-012 luminophore were recorded from the top side of the cell (i.e., from the electrolyte-air interface side) with a fiber-coupled spectrophotometer. The obtained spectra, corresponding to the typical luminescence spectra from L-012, are shown in Figure 4. As shown by the black curve, no luminescence was detected when the system was held in the dark. However, when the light from the LED was switched ON, FL emission from L-012 was recorded, as seen in the purple spectrum. Here, the intensity of the emission peak was 138 a.u. Finally, when a potential was applied to the $\mathrm{FTO} / \alpha-\mathrm{Fe}_{2} \mathrm{O}_{3}$, the overall luminescence reached a value of 385 a.u., at $\lambda_{\mathrm{em}}=498 \mathrm{~nm}$ which constitutes a 2.8 times amplification. This amplification is the result of the PECL generation coupled to the FL signal.

\subsection{PECL study}
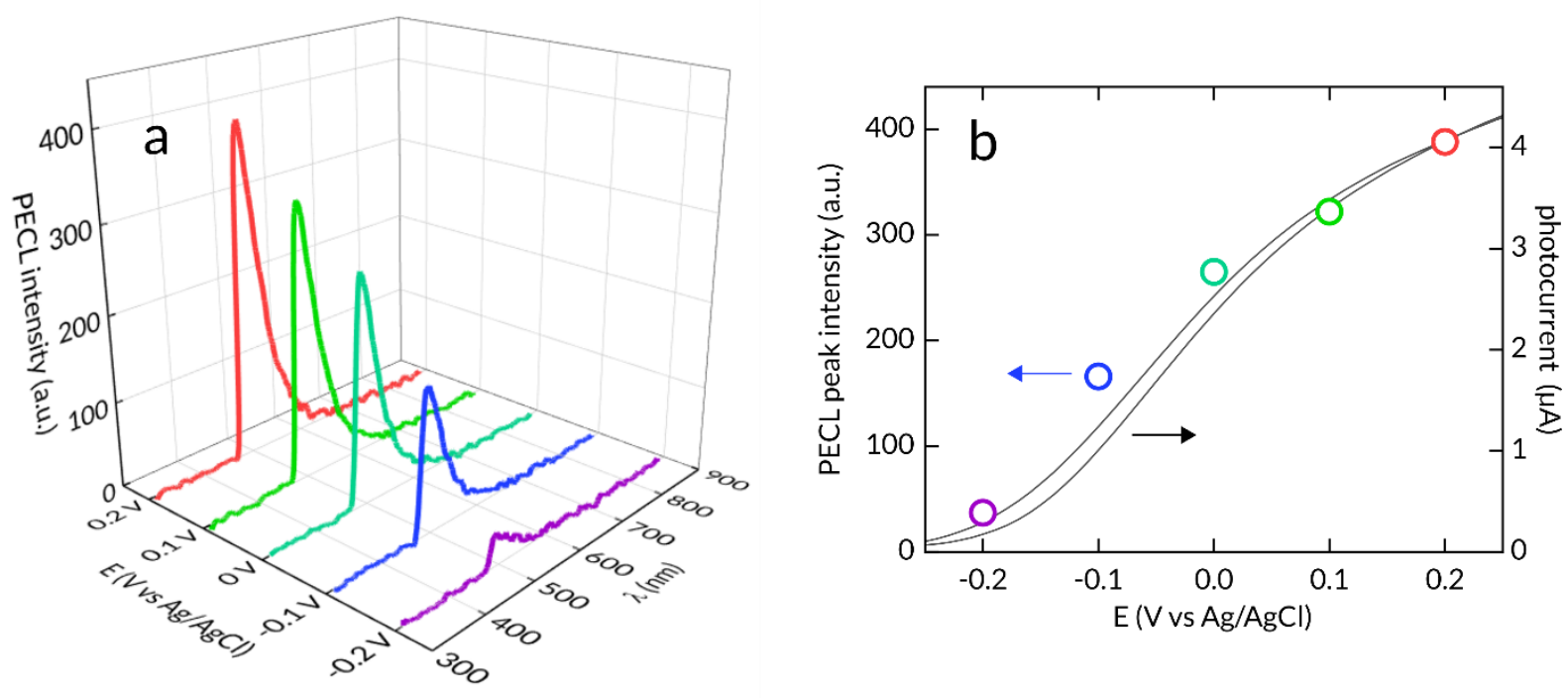

Figure 5. a) PECL spectra recorded with a constant LED illumination at different applied potentials E. b) Overlay of the intensity of the PECL peak (colored circles) and photocurrent (black curve) as a function of the imposed potential E. The PECL spectra and the intensity of the PECL peak were obtained by subtracting the FL spectra or FL peak values recorded under open-circuit potentials from the luminescence spectra (FL+PECL) or the luminescence peak values recorded under applied potential. All measurements were performed under LED illumination $\left(\lambda_{\mathrm{exc}}=375 \mathrm{~nm}\right)$ in $0.1 \mathrm{M} \mathrm{NaOH}$ with an L-012 concentration of $10 \mathrm{mM}$. 
Next, the PECL emission was investigated as a function of the applied potential. The PECL spectra, which were obtained by subtracting the FL signal from the overall emission are presented in Figure 5a. As it can be seen in this figure, clear PECL emission with $\lambda_{\text {em }}=498$ $\mathrm{nm}$ was detected starting from an applied potential of $-0.2 \mathrm{~V}$ with an intensity that increased to more than 10 times (from 37 to 388 a.u.) at $0.2 \mathrm{~V}$ vs $\mathrm{Ag} / \mathrm{AgCl}$. Moreover, Figure 5b demonstrates a clear relationship between PECL intensity and the photocurrent. The latter was calculated by subtracting the current of the voltammogram without LED illumination (black curve of Figure 3) from that of the signal under LED illumination (red curve of Figure 3). This cross-correlation between PECL and the photocurrent demonstrates clearly that PECL originates from the interfacial hole transfer that likely causes L-012 oxidation at the $\alpha$ $\mathrm{Fe}_{2} \mathrm{O}_{3} /$ liquid interface, although interfacial $\mathrm{pH}$ variation (caused by the concomitant oxygen evolution reaction (OER)) may also play a role in the PECL process.

As shown in Figure 6a (recorded at $-0.3 \mathrm{~V}$ ), no PECL was detected at lower potentials, because of the absence of oxidation current at these potentials, even under LED illumination (red curve of Figure 3 corresponding to the voltammetric response). Conversely, Figure $6 \mathrm{~b}$ (recorded at $0.3 \mathrm{~V}$ ) shows that ECL was detected above this potential range, caused by the apparition of a dark ECL current, at such bias, as seen in the voltammogram recorded with illumination OFF (black curve of Figure 3). These results show that it is possible to trigger PECL at $\alpha-\mathrm{Fe}_{2} \mathrm{O}_{3}$ at a potential as low as $-0.2 \mathrm{~V}$ vs $\mathrm{Ag} / \mathrm{AgCl}$. 


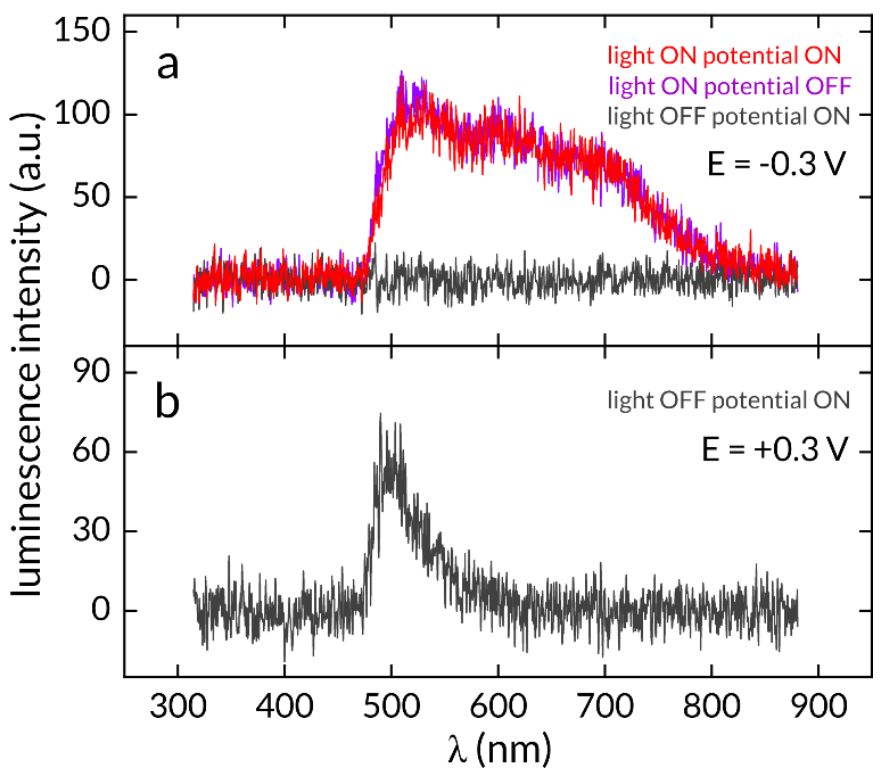

Figure 6. a) Luminescence spectra recorded at $-0.3 \mathrm{~V}$ in the dark (black curve), at open circuit under LED illumination (purple curve), and at $-0.3 \mathrm{~V}$ under LED illumination (red curve). $\mathrm{b}$ ) Luminescence spectrum recorded at $+0.3 \mathrm{~V}$ in the dark. The measurements were recorded in $0.1 \mathrm{M} \mathrm{NaOH}$ with an L-012 concentration of $10 \mathrm{mM}$.

Finally, the PECL stability was assessed on this system by monitoring the luminescence intensity as a function of time under intermittent LED illumination. As reported in Figure 7a, luminescence (FL + PECL) responds instantaneously to illumination and could be observed for $2 \mathrm{~h}$, however, the luminescence intensity faded by $35 \%$ over this rather long period. The origin of this decay was investigated by voltammetry after the 2 h-long test. As shown in Figure $7 \mathrm{~b}$, the current intensity recorded by LSV after the prolonged stability test also decayed when compared to that recorded before the test, in good agreement with a PECL decrease induced by a degradation of the photoanode in these experimental conditions. Such a trend may originate from photoanodic degradation [38] of the coating or an increase of surface states and electron-hole recombination as a result of the prolonged electrolysis $[40,41]$. If these performances are slightly lower than that measured at $\mathrm{BiVO}_{4}$ photoanodes in 
similar conditions [36], such activity is, however, still considerably higher than that obtained at lower band-gap and much more unstable photoelectrodes [31,32,34,35].
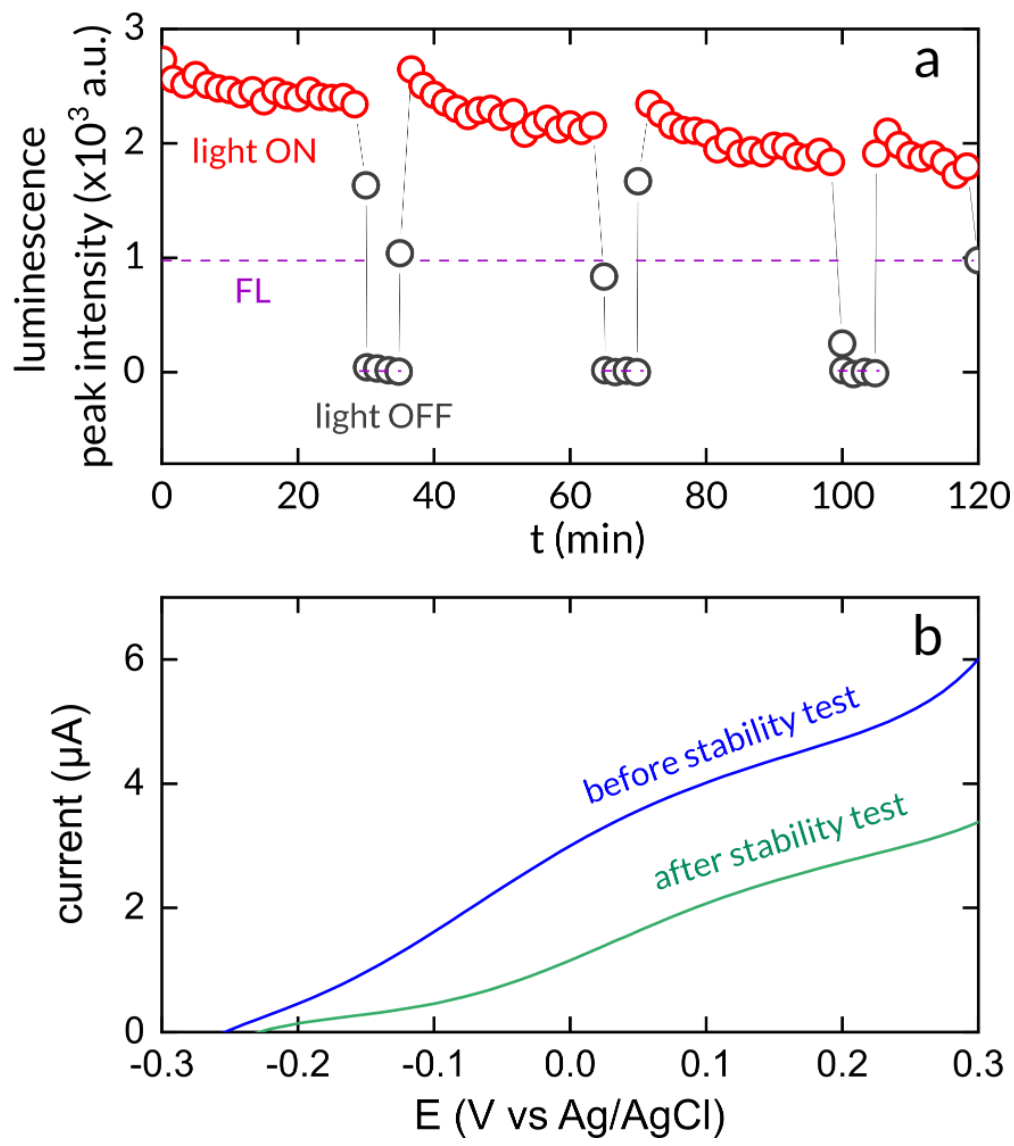

Figure 7. a) Stability of the luminescence signal over time. Graph showing the intensity of the luminescence peak as a function of the time at $\mathrm{E}=0 \mathrm{~V}$ under intermittent LED illumination. The intensity of the FL peak (light ON, potential OFF) is indicated by a purple dashed line. $b$ ) Linear sweep voltammograms (LSVs) recorded (blue curve) before and (green curve) after the stability test shown in Figure 7a. All measurements were performed under LED illumination $\left(\lambda_{\text {exc }}=375 \mathrm{~nm}\right)$ in $0.1 \mathrm{M} \mathrm{NaOH}$ with an L-012 concentration of $10 \mathrm{mM}$.

\section{Conclusion}

Photoinduced electrochemiluminescence (PECL) is an original concept that combines ECL and semiconductor photoelectrochemistry. In this article, we have reported the PECL of a luminol analog $(\mathrm{L}-012)$ on nanostructured $\alpha-\mathrm{Fe}_{2} \mathrm{O}_{3}$ photoanodes. Under illumination $\left(\lambda_{\text {exc }}=\right.$ 
$375 \mathrm{~nm}$ ) at potentials comprised between $-0.2 \mathrm{~V}$ to $0.2 \mathrm{~V}$ vs $\mathrm{Ag} / \mathrm{AgCl}$, photogenerated holes in $\alpha-\mathrm{Fe}_{2} \mathrm{O}_{3}$ oxidize $\mathrm{L}-012$, and generate the excited state of the monoanions of the 3aminophtalic acid. The excited state relaxes to the ground state emitting a blue photon. We employed an illumination wavelength $\left(\lambda_{\mathrm{exc}}=375 \mathrm{~nm}\right)$ lower than the emission wavelength $\left(\lambda_{\mathrm{em}}=498 \mathrm{~nm}\right)$, resulting in "fluorescence-type" PECL. This is the second example of this type of PECL [36], which differs from "upconversion-type" PECL [31]. We show that $\alpha$ $\mathrm{Fe}_{2} \mathrm{O}_{3}$ allows for PECL at applied potential as low as $-0.2 \mathrm{~V}$ vs $\mathrm{Ag} / \mathrm{AgCl}$ and that it can be used for luminescence amplification. Moreover, even if they exhibit signs of degradation, such structured $\alpha-\mathrm{Fe}_{2} \mathrm{O}_{3}$ photoanodes are active for hours, which should open up an interesting perspective for PECL, in particular for localized electrochemistry.

\section{Acknowledgements}

This work is funded by ANR (LiCORN - ANR-20-CE29-0006). S. Fryars, F. Gouttefangeas, and L. Joanny (ScanMAT, UMS 2011 University of Rennes 1-CNRS) are acknowledged for their help with the characterization of the samples. XRD and SEM were performed on ScanMAT facilities platforms (UMS 2001, University of Rennes 1-CNRS). J. Yu acknowledges the China Scholarship Council for her Ph.D. fellowship. 


\section{REFERENCES}

[1] Z. Liu, W. Qi, G. Xu, Recent advances in electrochemiluminescence, Chem. Soc. Rev. 44 (2015) 3117-3142.

[2] N. Sojic, Analytical electrogenerated chemiluminescence: from fundamentals to bioassays, The Royal Society of Chemistry, Cambridge, 2020.

[3] M. Hesari, Z. Ding, Review-electrogenerated chemiluminescence: light years ahead, J. Electrochem. Soc. 163 (2016) H3116-H3131.

[4] J. Zhang, S. Arbault, N. Sojic, D. Jiang, Electrochemiluminescence imaging for bioanalysis, Annu. Rev. Anal. Chem. 12 (2019) 275-295.

[5] C. Ma, Y. Cao, X. Gou, J.-J. Zhu, Recent progress in electrochemiluminescence sensing and imaging, Anal. Chem. 92 (2020) 431-454.

[6] H. Qi, C. Zhang, Electrogenerated chemiluminescence biosensing, Anal. Chem. 92 (2020) 524-534.

[7] Y. Wang, W. Guo, Q. Yang, B. Su, Electrochemiluminescence self-interference spectroscopy with vertical nanoscale resolution, J. Am. Chem. Soc. 142 (2020) 12221226.

[8] H. Ding, W. Guo, B. Su, Imaging cell-matrix adhesions and collective migration of living cells by electrochemiluminescence microscopy, Angew. Chemie Int. Ed. 59 (2020) 449-456.

[9] L.M. Moretto, T. Kohls, A. Chovin, N. Sojic, P. Ugo, Epifluorescence imaging of electrochemically switchable langmuir-blodgett films of nafion, Langmuir. 24 (2008) 6367-6374.

[10] M. Sentic, F. Virgilio, A. Zanut, D. Manojlovic, S. Arbault, M. Tormen, N. Sojic, P. Ugo, Microscopic imaging and tuning of electrogenerated chemiluminescence with boron-doped diamond nanoelectrode arrays, Anal. Bioanal. Chem. 408 (2016) 70857094.

[11] J.E. Dick, C. Renault, B.-K. Kim, A.J. Bard, Simultaneous detection of single attoliter droplet collisions by electrochemical and electrogenerated chemiluminescent responses, Angew. Chemie Int. Ed. 53 (2014) 11859-11862.

[12] M.W. Glasscott, J.E. Dick, Visualizing phase boundaries with electrogenerated chemiluminescence, J. Phys. Chem. Lett. 11 (2020) 4803-4808.

[13] K.N. Swanick, M. Sandroni, Z. Ding, E. Zysman-Colman, Enhanced electrochemiluminescence from a stoichiometric ruthenium(II)-iridium(III) complex soft salt, Chem. - A Eur. J. 21 (2015) 7435-7440.

[14] A. Zanut, A. Fiorani, S. Canola, T. Saito, N. Ziebart, S. Rapino, S. Rebeccani, A. Barbon, T. Irie, H.-P. Josel, F. Negri, M. Marcaccio, M. Windfuhr, K. Imai, G. Valenti, F. Paolucci, Insights into the mechanism of coreactant electrochemiluminescence facilitating enhanced bioanalytical performance, Nat. Commun. 11 (2020) 2668.

[15] A. Zanut, F. Palomba, M. Rossi Scota, S. Rebeccani, M. Marcaccio, D. Genovese, E. Rampazzo, G. Valenti, F. Paolucci, L. Prodi, Dye-doped silica nanoparticles for enhanced ecl-based immunoassay analytical performance, Angew. Chemie Int. Ed. 59 
(2020) 21858-21863.

[16] S. Voci, B. Goudeau, G. Valenti, A. Lesch, M. Jović, S. Rapino, F. Paolucci, S. Arbault, N. Sojic, Surface-confined electrochemiluminescence microscopy of cell membranes, J. Am. Chem. Soc. 140 (2018) 14753-14760.

[17] J. Shu, Z. Han, T. Zheng, D. Du, G. Zou, H. Cui, Potential-resolved multicolor electrochemiluminescence of n-(4-aminobutyl)-n-ethylisoluminol/tetra(4carboxyphenyl)porphyrin/ $/ \mathrm{TiO}_{2}$ nanoluminophores, Anal. Chem. 89 (2017) 1263612640.

[18] Y. Liu, W. Shen, Q. Li, J. Shu, L. Gao, M. Ma, W. Wang, H. Cui, Firefly-mimicking intensive and long-lasting chemiluminescence hydrogels, Nat. Commun. 8 (2017) 1003.

[19] C. Cui, R. Jin, D. Jiang, J. Zhang, J.-J. Zhu, Electrogenerated chemiluminescence in submicrometer wells for very high-density biosensing, Anal. Chem. 92 (2020) 578582.

[20] Y. Chen, D. Zhao, J. Fu, X. Gou, D. Jiang, H. Dong, J.-J. Zhu, In situ imaging facetinduced spatial heterogeneity of electrocatalytic reaction activity at the subparticle level via electrochemiluminescence microscopy, Anal. Chem. 91 (2019) 6829-6835.

[21] A. de Poulpiquet, B. Diez-Buitrago, M. Dumont Milutinovic, M. Sentic, S. Arbault, L. Bouffier, A. Kuhn, N. Sojic, Dual enzymatic detection by bulk electrogenerated chemiluminescence, Anal. Chem. 88 (2016) 6585-6592.

[22] Y. Wang, R. Jin, N. Sojic, D. Jiang, H.-Y. Chen, Intracellular wireless analysis of single cells by bipolar electrochemiluminescence confined in a nanopipette, Angew. Chemie Int. Ed. 59 (2020) 10416-10420.

[23] C.A. Marquette, L.J. Blum, Applications of the luminol chemiluminescent reaction in analytical chemistry, Anal. Bioanal. Chem. 385 (2006) 546-554.

[24] A. Kielland, T. Blom, K.S. Nandakumar, R. Holmdahl, R. Blomhoff, H. Carlsen, In vivo imaging of reactive oxygen and nitrogen species in inflammation using the luminescent probe L-012, Free Radic. Biol. Med. 47 (2009) 760-766.

[25] J. Zielonka, J.D. Lambeth, B. Kalyanaraman, On the use of L-012, a luminol-based chemiluminescent probe, for detecting superoxide and identifying inhibitors of NADPH oxidase: a reevaluation, Free Radic. Biol. Med. 65 (2013) 1310-1314.

[26] C. Cui, Y. Chen, D. Jiang, J.-J. Zhu, H.-Y. Chen, Attomole antigen detection using self-electrochemiluminous graphene oxide-capped Au@L012 nanocomposite, Anal. Chem. 89 (2017) 2418-2423.

[27] J. Zhang, R. Jin, D. Jiang, H.-Y. Chen, Electrochemiluminescence-based capacitance microscopy for label-free imaging of antigens on the cellular plasma membrane, J. Am. Chem. Soc. 141 (2019) 10294-10299.

[28] J. Zhou, G. Ma, Y. Chen, D. Fang, D. Jiang, H. Chen, Electrochemiluminescence imaging for parallel single-cell analysis of active membrane cholesterol, Anal. Chem. 87 (2015) 8138-8143.

[29] H. Gerischer, Solar photoelectrolysis with semiconductor electrodes, in: B.O. Seraphin (Ed.), Sol. Energy Convers. Solid-State Phys. Asp., Springer, Berlin, Heidelberg, 1979: 
pp. 115-172.

[30] M.X. Tan, P.E. Laibinis, S.T. Nguyen, J.M. Kesselman, C.E. Stanton, N.S. Lewis, Principles and applications of semiconductor photoelectrochemistry, in: K. D. Karlin (Ed.), Prog. Inorg. Chem. Wiley-VCH, Weinheim, vol. 41, 1994: pp. 21-144.

[31] Y. Zhao, J. Yu, G. Xu, N. Sojic, G. Loget, Photoinduced electrochemiluminescence at silicon electrodes in water, J. Am. Chem. Soc. 141 (2019) 13013-13016.

[32] Y.B. Vogel, N. Darwish, S. Ciampi, Spatiotemporal control of electrochemiluminescence guided by a visible light stimulus, Cell Reports Phys. Sci. 1 (2020) 100107.

[33] I.M. Terrero Rodríguez, A.J. Borrill, K.J. Schaffer, J.B. Hernandez, G.D. O’Neil, Light-addressable electrochemical sensing with electrodeposited n-silicon/gold nanoparticle schottky junctions, Anal. Chem. 92 (2020) 11444-11452.

[34] D. Laser, A.J. Bard, Semiconductor electrodes. Photo-induced electrogenerated chemiluminescence and up-conversion at semiconductor electrodes, Chem. Phys. Lett. 34 (1975) 605-610.

[35] J.D. Luttmer, A.J. Bard, Electrogenerated chemiluminescence. 34. Photo- induced electrogenerated chemiluminescence and up- conversion at semiconductor electrodes, J. Electrochem. Soc. 126 (1979) 414-419.

[36] J. Yu, H. Saada, R. Abdallah, G. Loget, N. Sojic, Luminescence amplification at $\mathrm{BiVO}_{4}$ photoanodes by photoinduced electrochemiluminescence, Angew. Chemie Int. Ed. 59 (2020) 15157-15160.

[37] G. Loget, Water oxidation with inhomogeneous metal-silicon interfaces, Curr. Opin. Colloid Interface Sci. 39 (2019) 40-50.

[38] D. Bae, B. Seger, P.C.K. Vesborg, O. Hansen, I. Chorkendorff, Strategies for stable water splitting via protected photoelectrodes, Chem. Soc. Rev. 46 (2017) 1933-1954.

[39] F. Le Formal, E. Pastor, S.D. Tilley, C.A. Mesa, S.R. Pendlebury, M. Grätzel, J.R. Durrant, Rate Law Analysis of Water Oxidation on a Hematite Surface, J. Am. Chem. Soc. 137 (2015) 6629-6637.

[40] L.M. Peter, A.B. Walker, T. Bein, A.G. Hufnagel, I. Kondofersky, Interpretation of photocurrent transients at semiconductor electrodes: Effects of band-edge unpinning, J. Electroanal. Chem. 872 (2020) 114234.

[41] L.M. Peter, K.G.U. Wijayantha, A.A. Tahir, Kinetics of light-driven oxygen evolution at $\alpha-\mathrm{Fe}_{2} \mathrm{O}_{3}$ electrodes, Faraday Discuss. 155 (2012) 309-322.

[42] K. Sivula, F. Le Formal, M. Grätzel, Solar water splitting: progress using hematite ( $\alpha$ $\mathrm{Fe}_{2} \mathrm{O}_{3}$ ) photoelectrodes, ChemSusChem. 4 (2011) 432-449.

[43] A.G. Tamirat, J. Rick, A.A. Dubale, W.-N. Su, B.-J. Hwang, Using hematite for photoelectrochemical water splitting: a review of current progress and challenges, Nanoscale Horizons. 1 (2016) 243-267.

[44] P. Sharma, J.-W. Jang, J.S. Lee, Key strategies to advance the photoelectrochemical water splitting performance of $\alpha-\mathrm{Fe}_{2} \mathrm{O}_{3}$ photoanode, ChemCatChem 11 (2019) 157179. 
[45] H. Saada, R. Abdallah, J.-F. Bergamini, S. Fryars, V. Dorcet, L. Joanny, F. Gouttefangeas, S. Ollivier, G. Loget, Photoelectrochemical sensing of hydrogen peroxide on hematite, ChemElectroChem 7 (2020) 1155-1159.

[46] Z. Li, C. Su, D. Wu, Z. Zhang, Gold nanoparticles decorated hematite photoelectrode for sensitive and selective photoelectrochemical aptasensing of lysozyme, Anal. Chem. 90 (2018) 961-967.

[47] D. Seo, S.Y. Lim, J. Lee, J. Yun, T.D. Chung, Robust and high spatial resolution light addressable electrochemistry using hematite $\left(\alpha-\mathrm{Fe}_{2} \mathrm{O}_{3}\right)$ photoanodes, ACS Appl. Mater. Interfaces. 10 (2018) 33662-33668.

[48] W. Wang, Z. Wang, Q. Zhu, G. Han, C. Ding, J. Chen, J.-R. Shen, C. Li, Direct electron transfer from photosystem II to hematite in a hybrid photoelectrochemical cell, Chem. Commun. 51 (2015) 16952-16955.

[49] P. Dias, A. Vilanova, T. Lopes, L. Andrade, A. Mendes, Extremely stable bare hematite photoanode for solar water splitting, Nano Energy. 23 (2016) 70-79.

[50] H.K. Mulmudi, N. Mathews, X.C. Dou, L.F. Xi, S.S. Pramana, Y.M. Lam, S.G. Mhaisalkar, Controlled growth of hematite $\left(\alpha-\mathrm{Fe}_{2} \mathrm{O}_{3}\right)$ nanorod array on fluorine doped tin oxide: Synthesis and photoelectrochemical properties, Electrochem. Commun. 13 (2011) 951-954.

[51] H.-J. Lewerenz, L. Peter, Photoelectrochemical water splitting, The Royal Society of Chemistry, Cambridge, 2014.

[52] W. Zhang, L. Hao, J. Huang, L. Xia, M. Cui, X. Zhang, Y. Gu, P. Wang, Chemiluminescence chitosan hydrogels based on the luminol analog L-012 for highly sensitive detection of ROS, Talanta 201 (2019) 455-459.

[53] N.S. Moyon, S. Mitra, Luminol fluorescence quenching in biomimicking environments: sequestration of fluorophore in hydrophobic domain, J. Phys. Chem. B. 115 (2011) 10163-10172.

[54] B. Smandek, G. Chmiel, H. Gerisher, Photoluminescence as an in- situ technique to determine solid state and surface properties of semiconductors in an electrochemical cell - application of the "dead layer model", Ber. Bunsenges. Phys. Chem. 93 (1989) 1094-1103.

[55] A. Wróblewska, O. V Reshetnyak, E.P. Koval'chuk, R.I. Pasichnyuk, J. Błażejowski, Origin and features of the electrochemiluminescence of luminol - experimental and theoretical investigations, J. Electroanal. Chem. 580 (2005) 41-49.

[56] W. Miao, Electrogenerated chemiluminescence and its biorelated applications, Chem. Rev. 108 (2008) 2506-2553. 
